\title{
Video-assisted nursing intervention: It's effectiveness on bullying prevention measures and procedures among primary school teachers
}

\author{
Afaf Abdel Malek Hussein ${ }^{1}$, Hayam Ahmed El Shrief ${ }^{2}$, Gehan Ahmed Abed ${ }^{3}$, Azza Abdalla Ghoneim ${ }^{4}$, Shimaa \\ AbdElhady Badawy*5 \\ ${ }^{1}$ Family and Community Health Nursing, Faculty of Nursing, Menoufia University, Egypt \\ ${ }^{2}$ Nursing Administration Department, Faculty of Nursing, Menoufia University, Egypt \\ ${ }^{3}$ Psychiatric Mental Health Nursing Department, Faculty of Nursing, Menoufia University, Egypt \\ ${ }^{4}$ Pediatric Nursing Department, Faculty of Nursing, Menoufia University, Egypt
}

Received: April 28, 2020

DOI: $10.5430 /$ jnep.v10n10p23
Accepted: June 21, 2020

Online Published: June 27, 2020

\begin{abstract}
Background: Bullying commonly defined as an aggressive behavior that is intentional, repeated for a long time and involves an imbalance of power. It can have negative effects on children's physical and psychological health and can even escalate to the tragedy of suicide. Aim: This study aimed to determine effectiveness of video-assisted nursing intervention on bullying prevention measures and procedures among primary school teachers.

Methods: A quasi-experimental design with pre and post-test was used. Sample: Simple random sample of 100 primary school teacher was included. Settings: The study was carried out at four primary schools in Shebin-Elkom and menouf, Menoufia Governorate, Egypt. Tools: Tool one: teachers' self-administered structured interview questionnaire (a) Demographic data (b) Teachers knowledge regarding bullying. Tool two: bullying preventive measures likert scale.

Results: The study showed that after video-assisted nursing intervention there was statistically significant improvement in the knowledge of primary school teachers' about bullying compared to before nursing intervention. Also, there was statistically significant improvement in teachers prevention practices regarding bullying after video-assisted nursing intervention compared to before nursing intervention. There was positive correlation between teachers' total knowledge scores and total practices scores about bullying post intervention.

Conclusions: Implementation of video-assisted nursing intervention achieved significant improvements in the primary school teachers' knowledge and practices measures regarding bullying prevention. Recommendations: Prominently utilizing videoassisted nursing intervention strategy in teaching bullying to promote children's health and improve knowledge and practices of teachers.
\end{abstract}

Key Words: Bullying, Video-assisted nursing intervention, Teachers

\section{INTRODUCTION}

Bullying conceptualized as a relationship problem, characterized by violent behavior for assaulting or harassing someone, and by imbalance of power between the involved parties. It is a complex and multi-determined phenomenon that defined as a range of verbally, physically, and relationally aggres-

\footnotetext{
*Correspondence: Shimaa AbdElhady Badawy; Email: gana_127@yahoo.com; Address: Pediatric Nursing Department, Faculty of Nursing, Menoufia University, Egypt.
} 
sive behaviors that occur repeatedly over an extended period against a victim. ${ }^{[1]}$ Bullying can extend from hitting, pushing, name-calling, threats, and mocking to extorting money and possessions. It can also be experienced directly (aggressions to victims in their presence) or indirectly (that usually happen in the absence of the victim, for example, spreading gossip, spoiling belongings, among others). ${ }^{[2]}$

According to World Health Organization (WHO) statistics, school bullying represent more than 13,000 middle school students between 2006 and 2008 in North Africa, while nationwide, $19 \%$ of students in grades 9-12 report being bullied on school. ${ }^{[3]}$ However, the rate of bullying reported in Egypt (60.3\%) was considerably higher than North African countries. ${ }^{[3,4]}$ This is due to the few previous studies had examined bullying in North Africa. The Egypt's National Center for Social and Criminal Research conducted a study about bullying among students in primary and secondary school and found that $69 \%$ of students reported being bullied or experiencing aggression from other students. ${ }^{[5]}$ They clarified that to socioeconomic inequalities, the home environment and other external forces were responsible for most acts of school violence, and noted that schools with students from a diversity of socioeconomic backgrounds experienced higher rates of school aggression. ${ }^{[5]}$

Bullying has an effect on physical and emotional health of children, both in the short term and long term. It can cause physical injury, social problems, emotional problems, and even death. Those who bullied are high risk for mental health problems, headaches, and problems adjusting to school. ${ }^{[6]}$ Also, it can cause damage to self-esteem later on. Children and adolescents who are bullies are risk for substance use, academic problems, and violence to others later in life. 2 . Both who are bullies and victims suffer the most serious effects of bullying and are at greater risk for mental and behavioral problems. Bullying is a major public health problem that requires continuous and coordinated time and attention of health-care providers, policy-makers and families. ${ }^{[7]}$

School nurses play a vital role in caring for students who bullied because they have a friendly relationship with students that is different from other employees. School nurses are often on the front lines of bullying, being the first adult, the victim and the bully go to for help. This makes nursing as the ideal profession to coordinate care for those involved in bullying episodes. The role of school nurse in regards to bullying include: Advocating for Students, educating students and staff, promoting equal access for students, avoiding labels, identifying at-risk students, creating a safe space, promoting activities that reduce bullying, engaging parents , and preventing violence. ${ }^{[8]}$
In primary schools, a school nurse can play a pivotal role by assessing, planning, and coordinating care for the victim and bully. School nurses are important healthcare professionals and the essential members of the bullying prevention team at each school. According to National Association of School Nurses (NASN), school nurses are principals in the development of school safety programs that address bullying and other school violence. ${ }^{[9]}$ This will result in fewer incidences of bullying, early identification of bullies and bullied victims, and safe school environment. School nurses are eager to learn about how to stop bullying. ${ }^{[10]}$

The National Association of School Nurses in 2014 reported that school nurses have the ability to work with school personnel and community members to create a safe school environment. This result in, children can learn without fear, express their emotions and solve problems. ${ }^{[11]}$ School nurses are responsible to the health and safety of children, and must identify children who bullied by others. School nurses can play a vital role in developing and implementing bullying prevention initiatives in schools. ${ }^{[12]}$

In addition, school's teacher and school have an important role in creating a safe school environment. Teachers should be trained to manage and prevent bullying incidences by using some commonly safeguard interventions which includes increased awareness of the problem, establishing clear rules and consequences, providing support to all students, providing adequate supervision, encouraging cooperation among students, and rewarding positive behaviors. Also, they must be in contact with the parent of children who engaged in bullying and monitor the school's bully-prevention program. ${ }^{[13]}$

Effective and efficient strategies for facing bullying depend on increasing knowledge and skills of teachers. Courses of raising skill of teachers towards classroom behavior and their efficiency in classroom behavior management are effective. ${ }^{[14]}$ It decreases potential negative consequences of bullying and victimization in school years such as depression and future delinquency. ${ }^{[15]}$ Today's technology has played a big role in changing the way that teachers learn, get entertained and how they teach their students. Use of advanced technology such as videotapes or computers is also popular now days. A video-assisted nursing intervention has three distinct parts. First, it considered a facilitator that guides the discussion. Second, the video cassette contains consistent current information. The third, it provides handouts for the participants so they can be actively involved in the process. $^{[16]}$

Many studies applied to study the effect of video assisted intervention. One of that studies examined teachers' reactions towards Video-Assisted Feedback. Results showed that 
teachers have a strong preference for feedback protocols that involve video, both in terms of effectiveness and ease of use. It also found evidence to suggest that video technology improves the quality of human feedback by helping in rapid recall of events and easier solving of conflicts. ${ }^{[13]}$ Another prospective study in Italy performed to evaluate the effects of an intervention program on the reduction of bullying and victimization in schools. Results showed that the program worked best for the students and concluded that interventions with videos and booklet help in increasing awareness and in reducing the effects bullying. ${ }^{[17]}$

Preventing bullying in schools requires the application of a wide range of evidence-based approaches. That includes, adopting clear anti-bullying policies, providing adequate adult supervision during unstructured time, training teachers to respond to bullying events effectively, promoting effective classroom management, using positive behavior support systems, providing supports to bullied children, monitoring bullying and increase accountability, involving families and communities, and integrating and sustaining prevention efforts. ${ }^{[18,19]}$

School team could be effective in preventing bulling and school nurse is one of the most important member. The nurse' responsibility is to provide knowledge, promote autonomy, contribute to health and living with the differences, identifying risk signs, behaviors and modalities of bullying and enhance quality of life of children. As well as encouraging and supporting schools in the implementation of programs for prevention and reduction of violence. ${ }^{[20,21]}$ The literatures showed the importance of coordinated work of nurses with teachers in preventing bullying among students. Recent studies indicate that the level of commitment of the teacher in carrying out interventions is an essential component to the success of preventing and combating school violence. ${ }^{[22]}$ The role of nurse regarding to preventing and coping with bullying involve actions directed exclusively to students, especially to victims, by techniques of dialogue/reflection, role playing, and development of coping skills among others. ${ }^{[23,24]}$ Nursing interventions about role of teachers in controlling and eradicating violence attitudes in class are rare. ${ }^{[20]}$ Therefore, the aim of the study was to determine effectiveness of video-assisted nursing intervention on bullying prevention measures and procedures among primary school teachers.

\subsection{Research hypotheses}

1) Knowledge of teachers' about school bullying would be improved after receiving video-assisted nursing intervention. 2) Teachers' practices about school bullying prevention measures and procedures would be improved after video-assisted Published by Sciedu Press nursing intervention.

\section{METHODS}

\subsection{Research design}

A quasi-experimental design was utilized to accomplish the aim of this study (pre and post-test).

\subsection{Settings}

This study was conducted at four primary schools in in Shebin-Elkom and menouf, Menoufia Governorate, Egypt. El-Shaheed Farouk El Talawy primary school, El-Salam primary school, Said EL-Hora primary school and Cedi-khames primary school.

\subsection{Subjects}

A simple random sample technique of 100 primary school teacher was obtained from the previous mentioned setting. All names of the teachers at every primary school were put in a bowl, and then randomly drawing out a number of 25 teachers from each school of the previously mentioned settings was done.

\subsection{Sample size}

In order to calculate the sample size required to conduct the study, the researchers used Epi website (Open Source Statistics for Public Health)*. Our sample size' Equation for primary school teachers was: $n=[D E F F * N p(1-p)] /\left[\left(d^{2} / Z 21-\right.\right.$ $\left.\alpha / 2 *(\mathrm{~N}-1)+\mathrm{p}^{*}(1-\mathrm{p})\right]$ where: DEFF is Design effect $=1$, Population size $(\mathrm{N})$ is 1000 primary school teachers. Frequency of knowledge ( from a pilot study) about bullying practices (P) is $7 \%+/-5 \%$, Confidence limits (d) is $5 \%$, and a power $(1-\beta)$ or (\% chance of detecting) of $80 \%$. The calculated sample size was 92 , which was approximated to 100 primary school teachers.

\subsection{Instruments}

Self-administered structured interview questionnaire: It was developed by the researchers after reviewing the related literature. This instrument was divided into two parts:

a. Demographic data of studied teachers': It included teacher's age, gender, position within the school and experience years of employment.

b. Teachers' knowledge about bullying. It contained 29 questions about bullying (3questions) general knowledge about bullying, (3 questions) forms of bullying, (6 questions) characteristics of victim, (7questions) characteristics of bully and (10) questions impacts of bullying on victims. The answer for each item was either yes-considered correct answer and given one score or no as a wrong answer and given zero. The 
total score of teacher's knowledge ranged from 0-29 points. Scoring system of teacher's knowledge about bullying.

\begin{tabular}{|l|l|}
\hline Poor knowledge $<50 \%$ & $0-14$ \\
\hline Fair knowledge 51\%-75\% & $15-21$ \\
\hline Good knowledge $>76 \%$ & $22-29$ \\
\hline
\end{tabular}

Bullying preventive measures likert scale: Questions about bullying prevention measures and procedures practiced by teachers from their perspectives. It was adapted from Al Qahtani' ${ }^{[25]}$ and Stauffer \& Sterling's studies ${ }^{[26]}$ then modified by the researchers. It was used to assess intervention and prevention strategies they would practice. It consisted of 20 statements ( 7 statements) bullying intervention practices, ( 5 statements) prevention practices at teacher level and (8 statements) prevention strategies at school level. The researchers were asked teachers to provide responses on a two-point Likert scale (disagree, agree) scored from 0 to 1 respectively. Then each component score was calculated and divided into poor/good practice.

\section{Total scoring system:}

\begin{tabular}{|l|l|}
\hline$(<75 \%)$ poor practice & $0-14$ \\
\hline$(\geq 75 \%)$ good practice & $15-20$ \\
\hline
\end{tabular}

\subsection{Validity and reliability}

\subsubsection{Validity}

For validity assurance, two instruments were provided to an expert team including one professor of pediatric nursing, two Professors in community health nursing, one professor in nursing Administration, one professor in psychiatric nursing two primary school teachers. The modifications was done to ascertain their relevance and completeness.

\subsubsection{Reliability}

The reliability of the instruments was done to determine the extent to which items in the questionnaire were related to each other by Cronbach's co-efficiency alpha for tool one $(\alpha$ $=0.82)$. while Pearson correlation co-efficiency was used to test the internal consistency $(r=0.02-0.98)$ for all items of tool two.

\subsection{Ethical considerations}

- All the ethical issues in conducting the study were followed by the researchers. An informed consent was obtained from the teachers who were willing to participate in the study.

- A pre assessment interview was done to inform teachers about the purpose, benefits of the study and participation in this study was voluntary and could withdraw at any time without penalty. They reassured that any obtained information would be strictly confidential. Also, a written approval was obtained from an ethic committee at faculty of nursing, Menoufia University, Egypt.

\subsection{Pilot study}

A pilot study was carried out on 10 primary school teachers to test the practicability, applicability, and feasibility of items in data collection tools. Modifications for some questions were done. The sample of the pilot study was excluded from the total sample.

\subsection{Procedure}

1-Data collection for this study was conducted for a period of 7 months extending from the 1 st of October 2018 to the end of April 2019.

2-Prior to data collection, a written permission to carry out the study was obtained from the director of each setting after submitting an official letter from the Dean of the faculty of Nursing at Menoufia University explaining the purpose of the study and methods of data collection.

3-The researchers were initiated data collection from teachers two days per week for two months through using selfadministered structured questionnaire.

4-The researchers selected appropriate videos on bullying to clarify it for teachers.

5-The researchers prepared a guide booklet about bullying definition, causes, forms, characteristics of victim, characteristics of bully, sings \& symptoms, impacts of bullying and bullying prevention intervention for students, parents, teachers and school after reviewing the related literature.

6-During the initial meeting with teachers, the researchers explained the purpose of the study and its benefits. Once they agreed to participate in the study, the researcher began collecting baseline data using the study instruments.

7-Teachers were informed about the schedule time and place for receiving video-assisted nursing intervention according to schools' schedule time.

8-Participants in each school (25subjects) were divided into two groups for attending intervention sessions according to their schedule time.

9-In the beginning, the researcher applied instrument one to assess teacher's knowledge and practices regarding bullying prevention. Instrument two was used to assess bullying preventive measures and procedures practiced by teachers from their perspectives.

10-Structured sessions about knowledge and practices regarding bullying prevention intervention through using videoassisted nursing intervention was implemented three times weekly with a total number of 6 sessions for each group within two weeks to assume 16 weeks for all subjects in the four selected settings. It was given in the school auditorium. 11-The researchers presented videos via the researcher's lab 
top through data-show for six sessions: the duration of each video was 5-10 minutes and the duration of each session was 30-45 minutes.

12-The first three sessions included videos about bullying definition, causes, forms, characteristics of victim, characteristics of bully and the impact of bullying.

13-The second three sessions included videos about teachers' practices about bullying intervention, prevention procedures at teacher, parents \& school level.

14-After each video session, the researcher presented data using power point about bullying definition, causes, forms, characteristics of victim, characteristics of bully, sings \& symptoms, impacts of bullying and bullying prevention intervention for students, parents, teachers and school.

15-The researchers gave copies of these videos to the teachers at the end of the data collection.

16-The researcher distributed a guide booklet about bullying to the teachers.

17-At the end of intervention period (two months), the researcher re-assessed teachers' knowledge and practices about bullying by the study instruments.

\subsection{Statistical analysis}

Data was coded and transformed into specially designed form to be suitable for computer entry process. Data was entered and analyzed by using SPSS (Statistical Package for Social Science) statistical package version 22. Graphics were done using Excel program. Quantitative data were presented by mean $(\bar{x})$ and standard deviation (SD). It was analyzed using paired t- test for comparison between two pre and post intervention' means. Qualitative data were presented in the form of frequency distribution tables, number and percentage. It was analyzed by chi-square $\left(\chi^{2}\right)$ test. However, if an expected value of any cell in the table was less than 5, Fisher Exact test was used Level of significance was set as $p$ value $<.05$ for all significant tests.

\section{Results}

Table 1 showed that, $64 \%$ of the studied teachers aged between 41 to 51 years, $67 \%$ of them females, $51 \%$ of them have experience of 21-31 years. As regards teaching grades, $48 \%$ of them were teaching to 4 th, 5 th, and 6th grades, and $10 \%$ were teaching to individual grades. Concerning positions hold in current school, majority (94\%) hold teachers, while only $5 \%$ were supervisors, and only one of them was a headmaster.

Figure 1 revealed that $67 \%$ of the studied teachers were female, while $33 \%$ of them were male.
Table 1. Distribution of demographic data of studied school teachers $(\mathrm{N}=100)$

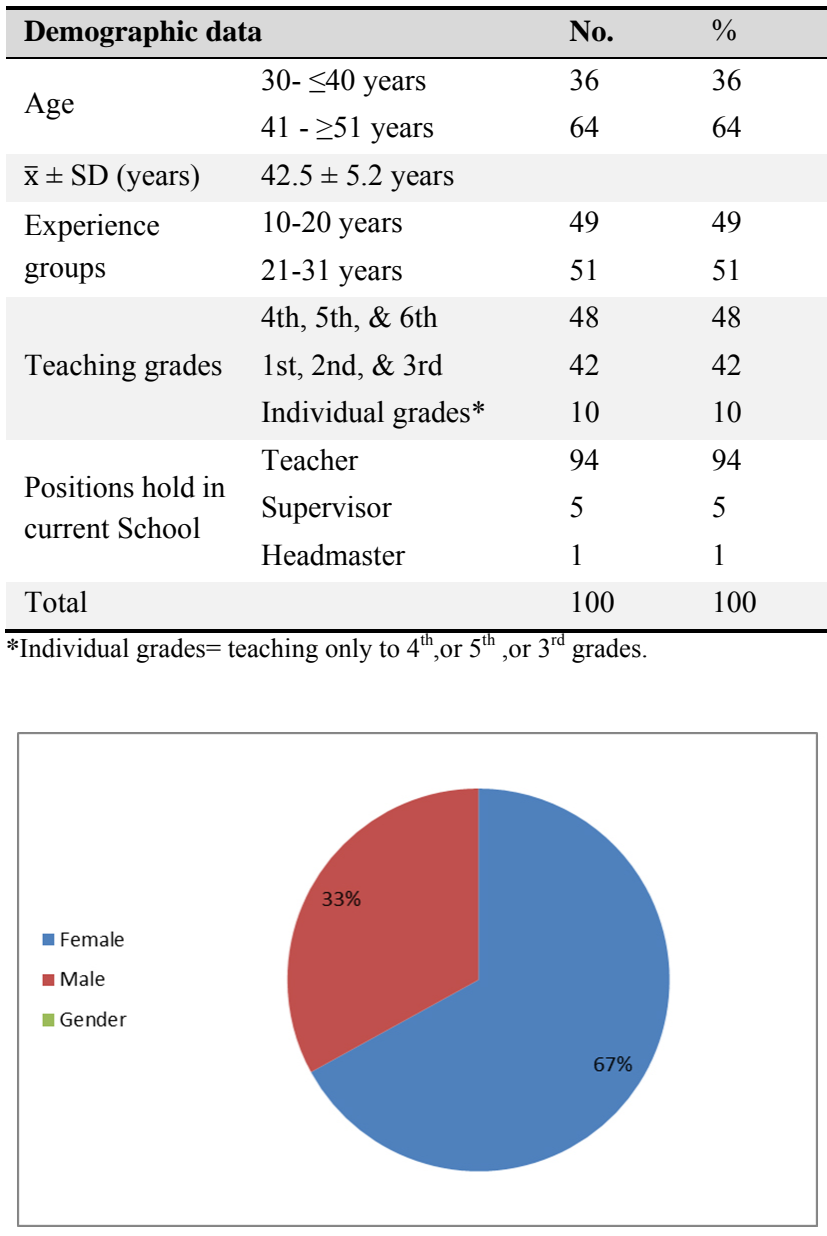

Figure 1. Distribution of gender of studied school teachers $(\mathrm{N}=100)$

Table 2 showed mean scores of teacher's knowledge about bullying on pre and post intervention. Mean scores on pre intervention were $11.0 \pm 6.8$ compared to $25.9 \pm 3.2$ on post respectively. There were obvious statistical significant differences between teachers 'knowledge at 0.001 level of statistical significance.

Table 3 showed Distribution of bullying prevention measures and procedure practiced from teachers' perspective on pre and post intervention. There was increase in numbers of teachers in post intervention than pre intervention in all items of teachers role in bullying prevention, bullying preventive measures and procedures practiced at teachers level and bullying prevention measures and procedures practices at school level. There was a significant difference between pre intervention percentages' and post intervention percentages' agree response $(p=.000)$. 
Table 2. Mean scores of teacher's knowledge about bullying on pre and post intervention $(\mathrm{N}=100)$

\begin{tabular}{|c|c|c|c|c|c|c|}
\hline \multirow{2}{*}{ Teacher's knowledge } & \multicolumn{2}{|c|}{ Pre intervention } & \multicolumn{2}{|c|}{ Post intervention } & \multirow{2}{*}{ Paired $t$ test } & \multirow{2}{*}{$p$} \\
\hline & Mean & \pm SD & Mean & \pm SD & & \\
\hline Teacher general knowledge about bullying: & 3.0 & \pm 1.6 & 5.3 & \pm 1.1 & 12.5 & $.000 * *$ \\
\hline Teachers' knowledge about characters of victims & 2.5 & \pm 1.9 & 5.1 & \pm 1.0 & 12.1 & $.000 * *$ \\
\hline Teachers' knowledge about characters of bullying & 2.6 & \pm 1.2 & 6.7 & \pm 1.5 & 14.3 & $.000 * *$ \\
\hline Teachers' knowledge about impact of bullying on victims & 2.9 & \pm 1.7 & 9.1 & \pm 1.1 & 20.7 & $.000 * *$ \\
\hline Teachers' grand total score of knowledge about bullying & 11.0 & \pm 6.8 & 25.9 & \pm 3.2 & 21.2 & $.000 * *$ \\
\hline
\end{tabular}

Table 3. Distribution of bullying preventive measures and procedure practiced by teachers on pre and post intervention

\begin{tabular}{|c|c|c|c|c|}
\hline \multirow{2}{*}{$\begin{array}{l}\text { Subcategories and items of bullying' prevention measures and } \\
\text { procedures }\end{array}$} & \multicolumn{2}{|c|}{$\%$ of agree perception } & \multirow{2}{*}{$\begin{array}{l}\chi^{2} \\
\text { test }\end{array}$} & \multirow[b]{2}{*}{$p$ value } \\
\hline & $\begin{array}{l}\text { Pre } \\
\text { intervention }\end{array}$ & $\begin{array}{l}\text { Post } \\
\text { intervention }\end{array}$ & & \\
\hline \multicolumn{5}{|l|}{ I-Teachers role in bullying prevention } \\
\hline 1-Take immediate action if bullying is observed & 25 & 94 & 65.02 & $p=.000 \mathrm{HS}$ \\
\hline 2-Bullying quickly resolved to avoid continued behavior & 35 & 95 & 18.5 & $p=.000 \mathrm{HS}$ \\
\hline 3-Provide support, guidance and alternatives to the victim. & 20 & 92 & 27.4 & $p=.000 \mathrm{HS}$ \\
\hline 4-Serious talks with the bully and the victim. & 40 & 87 & 25.7 & $p=.000 \mathrm{HS}$ \\
\hline 5-Managing bullying by rewarding for the positive change in bully behavior. & 15 & 96 & 57.04 & $p=.000 \mathrm{HS}$ \\
\hline 6- Escalating to the students’ parents & 45 & 96 & 19.08 & $p=.000 \mathrm{HS}$ \\
\hline 7-Temporary expelling the bully from the school. & 35 & 80 & 26.41 & $p=.000 \mathrm{HS}$ \\
\hline \multicolumn{5}{|l|}{ II-A-Bullying prevention measures and procedures practiced at teachers level } \\
\hline 1-Establishing classroom rules against bullying with student participation & 15 & 99 & 55.8 & $p=.000 \mathrm{HS}$ \\
\hline 2-Conducting classroom meetings to discuss bullying and how to prevent it. & 21 & 99 & 32.5 & $p=.000 \mathrm{HS}$ \\
\hline 3-Establishing good and positive relationship with students. & 45 & 98 & 18.2 & $p=.000 \mathrm{HS}$ \\
\hline 4-Establishing accepted classroom behaviors that confirm respect. & 40 & 94 & 29.07 & $p=.000 \mathrm{HS}$ \\
\hline $\begin{array}{l}\text { 5-Carry out activities involving making vows (e.g. plays, games, films, } \\
\text { bicycling, drawing, etc.). }\end{array}$ & 15 & 97 & 57.80 & $p=.000 \mathrm{HS}$ \\
\hline \multicolumn{5}{|l|}{ II-B-Bullying prevention measures and procedures practices at school level } \\
\hline 1 Visual displays such as posters and pamphlets on anti-bullying technique. & 16 & 95 & 56.02 & $p=.000 \mathrm{HS}$ \\
\hline $\begin{array}{l}2 \text { Staff supervision of students in specific places such as playground - class - } \\
\text { toilets - corridors. }\end{array}$ & 45 & 99 & 17.3 & $p=.000 \mathrm{HS}$ \\
\hline $\begin{array}{l}3 \text { Staff training to facilitate what actions to take when confronted with } \\
\text { bullying situations }\end{array}$ & 15 & 87 & 42.06 & $p=.000 \mathrm{HS}$ \\
\hline $\begin{array}{l}4 \text { Outside help such as a psychologist or counselor usually working with the } \\
\text { children involved in bullying incidents. }\end{array}$ & 9 & 82 & 62.3 & $p=.000 \mathrm{HS}$ \\
\hline $\begin{array}{l}5 \text { Consultation with the whole school community (e.g., staff, students and } \\
\text { parents) on the anti-bullying movement at your school. }\end{array}$ & 9 & 90 & 64.5 & $p=.000 \mathrm{HS}$ \\
\hline $\begin{array}{l}6 \text { Conducting Class room discussions on how to prevent bullying with } \\
\text { students, parents, and administrators. }\end{array}$ & 16 & 97 & 55.9 & $p=.000 \mathrm{HS}$ \\
\hline 7 Display an anti-bullying video & 12 & 88 & 45.6 & $p=.000 \mathrm{HS}$ \\
\hline $\begin{array}{l}8 \text { school have clear policies for preventing and dealing with bullying } \\
\text { situations }\end{array}$ & 16 & 98 & 56.7 & $p=.000 \mathrm{HS}$ \\
\hline
\end{tabular}

Table 4 showed mean scores of bullying preventive measures and procedures practiced by teachers on pre and post intervention. Mean scores of bullying prevention measures and procedures practiced by teachers on pre and post intervention were $6.4 \pm 0.8$ compared to $2.2 \pm 1.3$ on post respectively. While, Mean scores of teachers roles in preventing bullying on pre intervention were $1.4 \pm 0.9$ compared to $4.9 \pm 0.4$ on post respectively. Also, mean scores of teacher's bullying preventive measures and procedures practiced at school level on pre and post intervention was improved. Mean scores on pre intervention were $1.4 \pm 0.6$ compared to $7.4 \pm 1.0$ on post respectively. There were obvious statistical significant differences between teachers 'practice about bullying at 0.001 level of statistical significance. 
Table 4. Mean scores of bullying preventive measures and procedures practiced by teachers on pre and post intervention $(\mathrm{N}$ $=100$ )

\begin{tabular}{|c|c|c|c|c|c|c|}
\hline \multirow{2}{*}{$\begin{array}{l}\text { Bullying prevention measures and } \\
\text { procedures. }\end{array}$} & \multicolumn{2}{|c|}{ Pre intervention } & \multicolumn{2}{|c|}{ Post intervention } & \multirow{2}{*}{ Paired $t$ test } & \multirow{2}{*}{$p$} \\
\hline & Mean & \pm SD & Mean & \pm SD & & \\
\hline Teachers roles in preventing bullying & 2.2 & \pm 1.3 & 6.4 & \pm 0.8 & 16.9 & $.000 \mathrm{HS}$ \\
\hline $\begin{array}{l}\text { Bullying preventive measures and procedures } \\
\text { practiced at teachers level }\end{array}$ & 1.4 & \pm 0.9 & 4.9 & \pm 0.4 & 25.3 & $.000 \mathrm{HS}$ \\
\hline $\begin{array}{l}\text { Bullying prevention measures and procedures } \\
\text { practiced at school level }\end{array}$ & 1.4 & \pm 0.6 & 7.4 & \pm 1.0 & 1.4 & $.000 * *$ \\
\hline
\end{tabular}

Table 5 showed mean scores of total bullying prevention measures and procedures practiced by teachers on pre and post intervention. Mean scores on pre intervention were $4.9 \pm 1.4$ compared to $18.6 \pm 29.2$ on post respectively. There were obvious statistical significant differences between teachers 'practice about bullying at 0.001 level of statistical significance.

Table 6 showed relation between teachers' knowledge and practices scores about bullying prevention intervention post intervention. There was obvious statistical significant differences between teachers 'knowledge and practice about bullying at 0.001 level of statistical significance.

Figure 2 showed correlation between total score of teachers' knowledge and practices about bullying prevention intervention post intervention. As indicated in the figure, there was positive correlation between teachers' total knowledge scores and total practices scores about bullying post intervention.

Table 5. Mean scores of total bullying prevention measures and procedures practiced by teachers on pre and post intervention $(\mathrm{N}=100)$

\begin{tabular}{|c|c|c|c|c|c|c|}
\hline \multirow{2}{*}{ Teachers' Practice } & \multicolumn{2}{|c|}{ Pre intervention } & \multicolumn{2}{|c|}{ Post intervention } & \multirow{2}{*}{ Paired $t$ test } & \multirow{2}{*}{$p$} \\
\hline & Mean & \pm SD & Mean & \pm SD & & \\
\hline Teachers' grand total score of practice & 4.9 & \pm 1.4 & 18.6 & \pm 1.6 & 29.2 & $.000 * *$ \\
\hline
\end{tabular}

Table 6. Relation between teachers' knowledge and practices scores about bullying prevention intervention post intervention

\begin{tabular}{|c|c|c|c|c|}
\hline \multirow[b]{2}{*}{ Post total knowledge scores } & \multicolumn{2}{|c|}{ Post total practices scores } & \multirow[b]{2}{*}{ Total } & \multirow[b]{2}{*}{$p$ value } \\
\hline & $\begin{array}{l}\text { Low practicing } \\
(0-14)\end{array}$ & $\begin{array}{l}\text { High practicing } \\
(15-20)\end{array}$ & & \\
\hline$<50 \%$ poor & 0 & 2 & 2 & \\
\hline knowledge (0-14) & $0.0 \%$ & $100.0 \%$ & $100.0 \%$ & \\
\hline $51-75 \%$ fair & 7 & 6 & 13 & \\
\hline knowledge (15-21) & $53.8 \%$ & $46.2 \%$ & $100.0 \%$ & $\mathrm{LR}=23.6, p=.000^{* *}$ \\
\hline$\geq 76 \%$ good & 2 & 83 & 85 & \\
\hline knowledge (22-29) & $2.4 \%$ & $97.6 \%$ & $100.0 \%$ & \\
\hline \multirow{2}{*}{ Total } & 9 & 91 & 100 & \\
\hline & $9.0 \%$ & $91.0 \%$ & $100.0 \%$ & \\
\hline
\end{tabular}

Note. LR $=$ Likelihood Ratio

\section{Discussion}

Bullying is a global concern and has been a constant problem since the creation of schooling. When large numbers of children are constrained together in the same environment for some period, it is likely that some abuse of power may occur Published by Sciedu Press in relationships. ${ }^{[27]}$ School bullying is one such problem which has been the focus of attention in recent years, partly due to the intense media coverage following events, such as school shootings and suicides. ${ }^{[28]}$ This study aimed to determine effectiveness of bullying prevention intervention among primary school teachers using video-assisted teaching. 


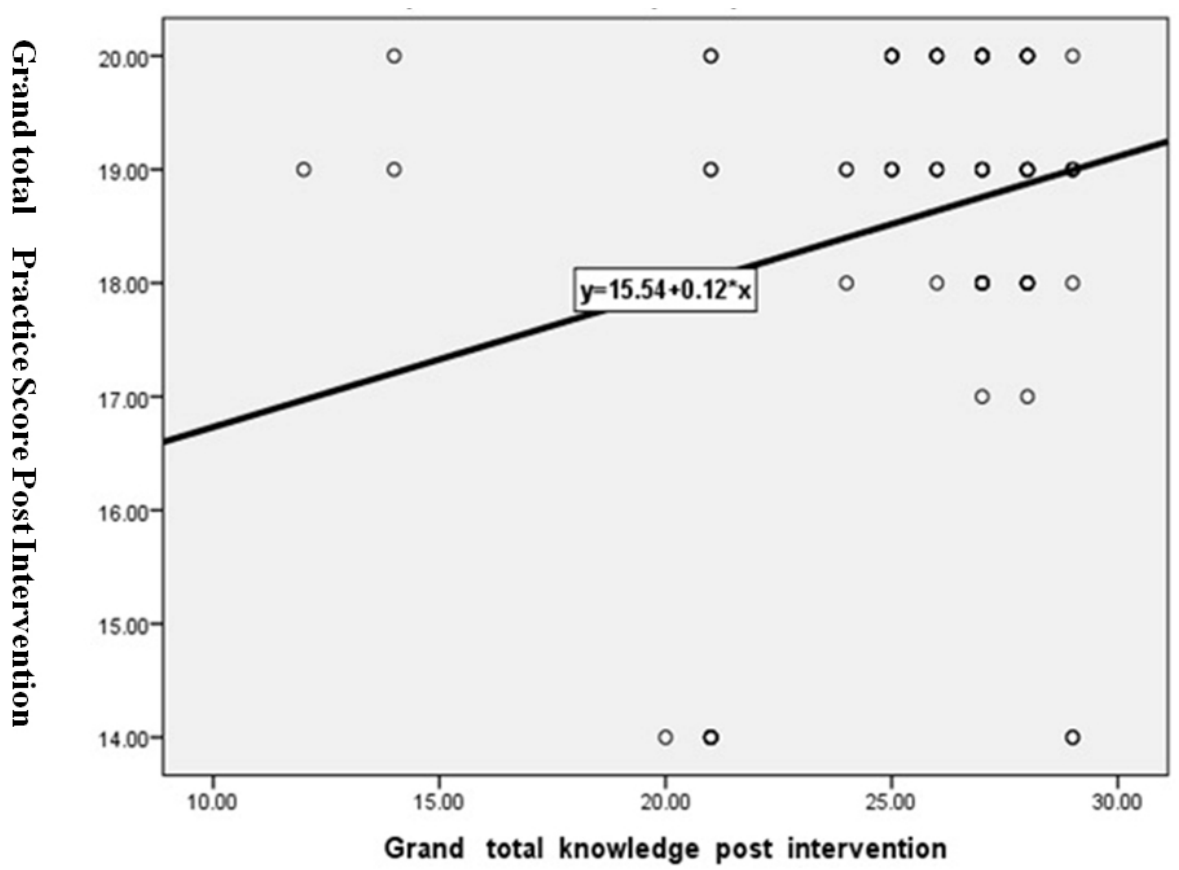

Figure 2. Correlation between total score of teachers' knowledge and practices about bullying post intervention

The current study hypothesized that teachers will have higher knowledge about bullying on post- test than pre-test. The teachers have higher general knowledge about bullying on post-test than on pre-test, the present study illustrated that regarding all level of teacher's knowledge about bullying was significantly improved with the intervention on posttest. However, it could be inferred that the guidelines helped teachers to improve their knowledge about bullying that confronted them during their work in school. This could be rationalized as the researcher used different educational strategies (oral presentations, group discussion, videos and explanatory booklets). This result comes in agreement with Ford et al. ${ }^{[16]}$ Who mentioned that there was significant improvement in teachers' knowledge about bullying after education and training. Those results may be contributed to prove the best effect of using video technology in teaching.

However, this study revealed that the lowest level of teachers' knowledge was on pre-test. This result was same line with Ansary et al. ${ }^{[29]}$ who stated that most teachers were not fully aware of bullying that differentiates it from playful teasing. However, they had good awareness about the cause and types of bullying after giving video-assisted teaching to school teachers. In addition, the study result congruent with Monica ${ }^{[13]}$ who mentioned that majority of the subjects had low knowledge on bullying in pre-test and the overall post-test knowledge scores shows that all the subjects have adequate knowledge regarding bullying. This finding could be due to the absence of teaching courses about bullying since their graduation and lack of years of experience in bullying intervention.

Concerning, teachers' level of knowledge about impact of bullying on the victims, the current study revealed that after video- assisted nursing intervention, there was highly statistical significance difference between pre and post intervention. This result was consistent with Hazlerr et al. ${ }^{[30]}$ who reported that the teacher s' knowledge level about impact of bullying on victim improved after receiving training than before it. Also, the study finding consistent with Craig ${ }^{[31]}$ who illustrated that a highly statistical significance difference of teachers' knowledge level about effect of bullying on victims post providing instruction for teachers than before instructions. This revealed that training program was effective in increasing information and skills of teachers about bullying.

Regarding to bullying prevention measures and procedures practices by teachers pre and post intervention there was a highly statistical significance difference between pre and post intervention. This indicated that the video-assisted nursing intervention method which introduced by the researchers occurred improvement in teacher's practices about bullying prevention than before teaching. This study was in the same context with Ferguson et al. ${ }^{[32]}$ who reported that the treatment was able to create significant changes in teachers' practices about bullying intervention and prevention compared to the control group. In addition, these findings agreed with Ball ${ }^{[33]}$ who mentioned that anti-bullying program could be effective 
on bullying behavior management strategies and teachers 'practice about bullying intervention and prevention. In addition, the study result was in the same line with Bauman et al. ${ }^{[34]}$ who illustrated that anti-bullying training for teachers and other school members improved practices of them about intervention and prevention of bullying. Therefore, awareness through different kinds of educational programs and implementing multiple approaches targeting bullying is the best strategy to prevent bullying. Bedsides, interventions with assisted devices as videos and booklet help to increase awareness and reduce the effects bullying.

The present study results revealed that there were positive correlation between teachers' total knowledge scores and teachers' total practice scores about bullying prevention . This result in the same line with Ansary et al. ${ }^{[29]}$ who stated that The overall post test knowledge scores shows that all the subjects have adequate knowledge regarding bullying and their practice about bullying prevention. In the same line, the study completed by Ansary et al. ${ }^{[29]}$ who concluded that every incident of school bullying may not be preventable, however, it suggested that proper implementation and execution of an effective school bulling prevention significantly lowers the incidents of and potential for bullying. videoassisted nursing interventionfor school teachers introduced highly improvement in teachers' knowledge level about bullying and their practice about prevention strategies. Video teaching has been shown to be a valuable tool in improving performance.

\section{Conclusion}

Implementation of video-assisted nursing intervention achieved significant improvements in the primary school teachers' knowledge and practices measures regarding bullying prevention.

\section{Recommendations}

1) Nurses can use this video-assisted nursing intervention to educate teachers as well as parents.

2) Ongoing in-service education programs about bullying intervention and preventive practices should be designed and implemented at all schools based on the teachers' actual needs.

3) The same study could be applied on a large group of teachers to ensure the generalization of the results.

4) Further research can be done on creating awareness among parents about bullying and its effect on student's achievement level.

\section{ACKNOWLEDGements}

Our great thanks submitted to ALLAH who provided us with the ability to complete this work. We would like to offer special thanks to school' teachers and school administration for their participation and cooperation to complete this study.

\section{CONFLICTS OF INTEREST Disclosure}

The author declares that there is no conflict of interest statement.

\section{REFERENCES}

[1] Olweus D. Cyberbullying: An overrated phenomenon? European Journal of Developmental Psychology. 2012; 9: 520-538. https: //doi.org/10.1080/17405629.2012.682358

[2] Centers for disease control and prevention. Bullying in Schools: The Power of Bullies and the Plight of Victims. Annual Review of Psychology. 2017; 65: 159-85. PMid:23937767 https://doi .org/10 .1146/annurev-psych-010213-115030

[3] Due P, et al. Socioeconomic inequality in exposure to bullying during adolescence: a comparative, cross-sectional, multilevel study in 35 countries. American Journal of Public Health. 2009; 99(5): 907-913. PMid:19299676 https://doi.org/10.2105/AJPH. 2008.1393 03

[4] Fleming LC, Jacobsen KH. Bullying among middle-school students in low and middle income countries. Health Promotion International. 2010; 25(1): 73-84. PMid:19884243 https://doi.org/10.109 3/heapro/dap046

[5] Zayed A, et al. [Violence among students in schools]. Cairo, National Center for Social and Criminal Research, 2004 [In Arabic].

[6] Abdirahman, Fleming, Jacobsen. Parental involvement and bullying among middle school students in North Africa. Eastern Mediterranean Health Journal. 2012; 19(3): 1-7.
[7] Brank EM, Hoetger LA, Hazen KP. "Bullying". Annual Review of Law and Social Science. 2012; 8(1): 213-230. https ://doi.org/ 10.1146/annurev-lawsocsci-102811-173820

[8] Hymel S, McClure R, Miller M, et al. Addressing school bullying: Insights from theories of group processes. J Appl Dev Psychol. 2015; 37(1): 16-24. https://doi.org/10.1016/j.appdev.2014.11 .008

[9] Tolsma J, van Deurzen I, Stark TH, et al. Who is bullying whom in ethnically diverse primary schools? Exploring links between bullying, ethnicity, and ethnic diversity in Dutch primary schools. Soc Networks. 2013; 35(1): 51-61. https://doi.org/10.1016/j.so cnet.2012.12.002

[10] Davis K, Randall DP, Ambrose A, et al. "I was bullied too": stories of bullying and coping in an online community. Information, Commun Soc. 2015 ; 18(4): 357-75. https://doi.org/10.1080/136911 $8 X .2014 .952657$

[11] Smith BH, Low S. The Role of Social-Emotional Learning In Bullying Prevention Efforts. Theory Pract. 2013; 52(4): 280-7. https://doi.org/10.1080/00405841.2013.829731

[12] Thornberg R, Jungert T. Bystander behavior in bullying situations: Basic moral sensitivity, moral disengagement and defender self- 
efficacy. J Adolesc. 2013; 36(3): 475-83. PMid:23522703 https: //doi.org/10.1016/j.adolescence. 2013.02.003

[13] Monica MS. A study to Assess The effectiveness of Video Assisted Teaching for Teachers on School Bullying in Selected Schools Bangalore, Master thesis. Universal College of Nursing, Bangalore. 2013.

[14] Cross D. Beyond bullying: Positive Change for all, Telethon Kids Institute. 2017. Available from: https://www.telethonkids.o rg.au/our-research/brain-and-behaviour/development - andeducation/health-promotion-and-education/beyon d-bullyingpositive-change-for-all/

[15] McGilloway S, Mhaille G, Lodge A, et al. Positive classrooms: Positive children; a randomized controlled trial to investigate the effectiveness of the incredible years teacher classroom management training program in an Irish context (short term outcomes). [cited 12 April 2011].

[16] Ford T, Edwards E, Sharkey S, et al. Supporting teachers and children in schools: the effectiveness and cost-effectiveness of the incredible years teacher classroom management program in primary school children. J Public Health. 2012; 12: 719. PMid:22935476 https://doi.org/10.1186/1471-2458-12-719

[17] Brockenbrough KK. Bullying prevention among middle school students. Dissertation Abstracts International: Section B: The Sciences and Engineering; 2001; 62(1-B): 538.

[18] Polanin M, Vera E. Bullying Prevention and Social Justice. Theory Pract. 2013; 52(4): 303-10. https://doi.org/10.1080/004058 41.2013 .829736

[19] Holt MK, Raczynski K, Frey KS, et al. School and CommunityBased Approaches for Preventing Bullying. J Sch Violence. 2013; 12(October): 238-52. https://doi.org/10.1080/15388220.2 013.792271

[20] Mendes CS. Preventing school violence: an evaluation of an intervention program. Rev Esc Enferm USP [Internet]. 2011 [cited 2013 jul. 25]; 45(3): 581-8. PMid:21710061 https : //doi .org/10.159 0/S0080-62342011000300005

[21] Perron T. Peer victimisation: strategies to decrease bullying in schools. Br J Sch Nurs. 2013; 8(1): 25-9. https ://doi .org/10.1 2968/bjsn.2013.8.1.25

[22] Craig K, Bell D, Leschied A. Pre-service teachers' knowledge and attitudes regarding school-based bullying. Can J Educ. 2011; 34(2): 21-33.

[23] Joronen K, Häkämies A, Astedt-Kurki P. Children's experiences of a drama programme in social and emotional learning. Scand J Caring
Sci. 2011; 25(4): 671-8. PMid:21362006 https://doi.org/10.1 $111 / j .1471-6712.2011 .00877 . x$

[24] Vessey JA, O'Neill KM. Helping students with disabilities better address teasing and bullying situations: a MASNRN study. J Sch Nurs. 2011; 27(2): 139-48. PMid:20956579 https ://doi.org/10 $.1177 / 1059840510386490$

[25] AlQahtani NSS. The extent of elementary female teachers awareness about bullying and actual measures and procedures followed to prevent it in government schools in Riyadh from their perspective. ASEP. 2015; 2090-7605.

[26] Stauffer SV. High School Teachers' Perceptions of Cyber Bullying Prevention and Intervention Strategies. 2011. All Theses and Dissertations.

[27] Monks CP, Coyne I. Bullying in different contexts. Cambridge: Cambridge University Press; 2011.

[28] Abdirahman, Fleming, Jacobsen. Teachers' Perceptions of Bullies and Bullying Behavior. OISE University of Toronto. 2012.

[29] Ansary N, Elias M, Greene M, et al. Guidance for schools selecting anti-bullying approaches: Translating evidence based strategies to contemporary implementation realities. Educational Researcher. 2015; 44(1): 27-36. https ://doi .org/10.3102/0013189X1456 7534

[30] Hazlerr RJ, Carney JV, Green S, et al. Areas of Expert Agreement on Identification of School Bullies and Victims. School Psychology International. 1997; 18(1): 5-14. https://doi.org/10.1177/01 43034397181001

[31] Craig WM. The relationship among bullying, victimization, depression, anxiety, and aggression in elementary school children. Personality and Individual Differences. 1998; 24(1): 123-130. https : //doi.org/10.1016/S0191-8869(97)00145-1

[32] Ferguson CJ. Video Games and Youth Violence: A Prospective Analysis in Adolescents. (PDF). Journal of Youth and Adolescence. 2011; 40(4): 377-91. PMid:21161351 https://doi.org/10.1007/s1 0964-010-9610- $\mathrm{x}$

[33] Ball HA. Genetic and environmental influences on victims, bullies and bully-victims in childhood. Journal of Child Psychology and Psychiatry. 2008; 49(1): 104-12. PMid:18181884 https ://doi .or $\mathrm{g} / 10.1111 / \mathrm{j} .1469-7610.2007 .01821 . \mathrm{x}$

[34] Bauman S, Del Rio A. Pre-service teachers' responses to bullying scenarios: Comparing physical, verbal, and relational bullying. Journal of Educational Psychology. 2006; 98(1): 219-231. https://doi.org/10.1037/0022-0663.98.1.219 